\title{
CIRCADIAN RHYTHM IN THE TROPICAL ANT ECTATOMMA (HYMENOPTERA: FORMICIDAE)*
}

\author{
By Elwood S. McCluskey
}

Biology and Physiology Departments, Loma Linda University, Loma Linda, CA 92350

\section{INTRODUCTION}

In early 1960 I surveyed the daily activity rhythms of three tropical ponerine ants, Paraponera clavata, Ectatomma tuberculatum, and E. ruidum, first on Barro Colorado Island (BCI), Panama, then in the laboratory upon return home. The study of Paraponera was reported previously (McCluskey \& Brown 1972). That of Ectatomma presented here is of interest in spite of being based on limited material, because it is one of the few studies of rhythmicity of ants in controlled conditions; the two species appeared opposite in time-ofday out of the nest, in both field and laboratory; and the rhythm of E. tuberculatum persisted in constant conditions.

\section{MethodS AND MATERIALS}

All the observations for either species, whether field or laboratory, were on one nest (except Fig. 1, field E. ruidum, two nests); hence the conclusions are based on replicate days, rather than nests.

In the field, the best ant counts for the tuberculatum nest were on an adjacent vine, whereas the counts for ruidum were mostly on the ground. This accords with Levings \& Franks' (1982) statement that $E$. ruidum forages mainly at ground level, whereas $E$. tuberculatum forages mainly at shrub level. Night counts were made by dim red flashlight.

At the end of January workers from the tuberculatum nest and from one of the two ruidum nests were taken back to E. O. Wilson's laboratory at Harvard. They were kept in a darkroom at a constant temperature of $27.5 \pm 1.5^{\circ} \mathrm{C}$. (The shaded ground temperature on $\mathrm{BCI}$ averages $25-26^{\circ} \mathrm{C}$ all year [Levings 1983].) In alternating light and darkness (LD) there was fluorescent light, 400 lux, for 12 hours

*Manuscript received by the editor June 24, 1987. 
daily. There was clear ruby light during the dark hours, and continuously during constant darkness (DD).

The group of ants of each species was placed in a two-chambered nest. Each chamber was a clear plastic box about $10 \mathrm{~cm}$ in diameter and depth. One chamber was darkened and had water and sugar water provided; the other served as an arena, dry and fully exposed to the light regime, and the counts were made there. To avoid interference with the ant rhythms, food was renewed only when observations were to be omitted for the following hours or days.

\section{RESULTS}

\section{Field}

Figure 1 shows the number of $E$. tuberculatum out, as assayed on the vine. A prominent increase occurred at dusk. The number was high during at least the first half of the night, and was low from dawn through the day. Fewer counts were made in the rest of the area around the nest entry (not shown), but they corroborated the high-night, low-day pattern.

The pattern for E. ruidum, on the other hand, was diametrically opposite, high in the day and low at night, as based on two nearby nests of ruidum observed on the same days as tuberculatum (Fig. 1).

\section{Laboratory Light and Dark}

The number of $E$. tuberculatum out in the arena started rising from soon after light-off, to the highest peak early in the night (Fig. 2). The number fell after the lights came on, remaining low through the light period, as in the field. The rise after light-off and the fall after light-on had also been seen in LD over a month earlier, good because so soon after collection from the field (but not shown here because so few night counts were made then).

The E. ruidum counts were higher in the light period than at night (Fig. 2), and thus opposite to tuberculatum observed the same days.

\section{Constant Darkness}

What is the evidence for persistence of rhythm in the absence of the light-dark cycle? For each of the first 3 days of DD (Feb. 9-11), ant counts were made during what had been the light and the first of the dark part of the LD cycle. There was no obvious rhythm for $E$. ruidum, possibly because of so low a number of ants out in the 


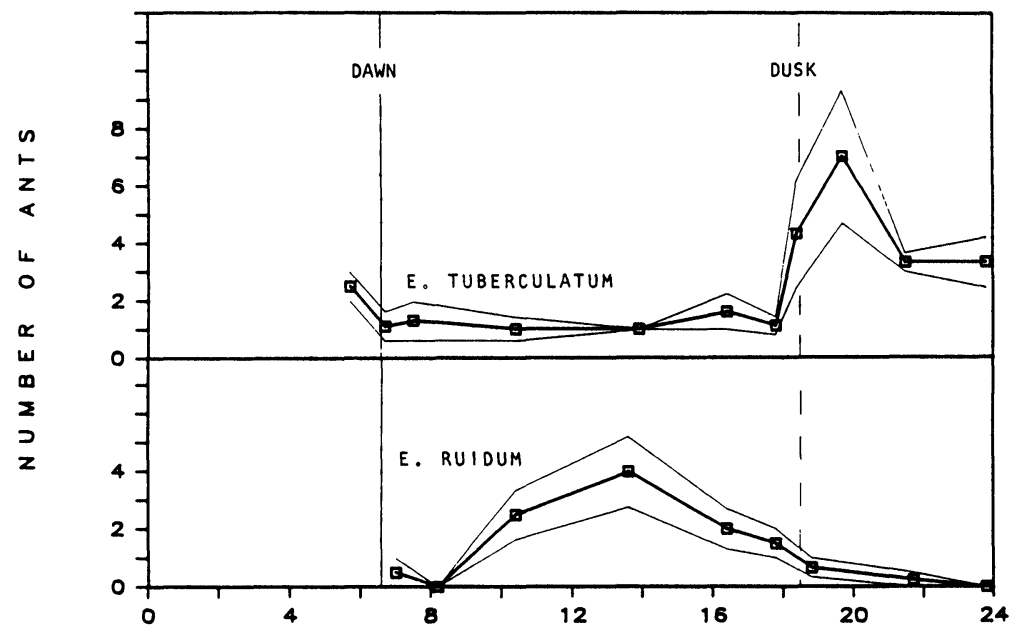

Fig. 1. Above-ground field rhythm on BCI. E. tuberculatum, ants on vine within $2 \mathrm{~m}$ of nest; mean $\pm S E, n=3-4$ (i.e., each mean is based on 3-4 days as replicates for given hour on graph), Jan. 10-11 and 17-21; P $<.01$ for difference among hours (one-way ANOVA). E. ruidum, 2 nests, ants within $.5 \mathrm{~m}$ of nest. $\mathrm{N}=2-4$ (nest and/or day replicates), Jan. $10-11$ and 17-19; $P=.01$.

arena, always in contrast with the high number for tuberculatum; and the record is not shown.

E. tuberculatum was checked in two ways, DD following LD, and DD following light exposure at night. Fig. 3 serves to illustrate both, because the patterns were similar relative to what had been the light period. In DD (Feb. 9-11) following LD the arena count resembled that in LD in that it was low near what had been the light-on hour and high near what had been light-off. The data are too few to compute an accurate free-running period; but for the total 3-day span of counts a cosine least-squares fit (Halberg et al. 1972) to a trial period of 24 hours is good $(P<.01)$, thus suggesting a persistent rhythm. And the counts for the various times of day differ consistently (using the 3 days as replicates, ANOVA $\mathrm{P}<$ .001 ), again suggesting persistence.

If rhythmicity is truly endogenous it should still appear after reversal of day-night phase. So the lights were turned on at $2000 \mathrm{Feb}$ 13 for 12 hours (i.e., through the night), then left off continuously 


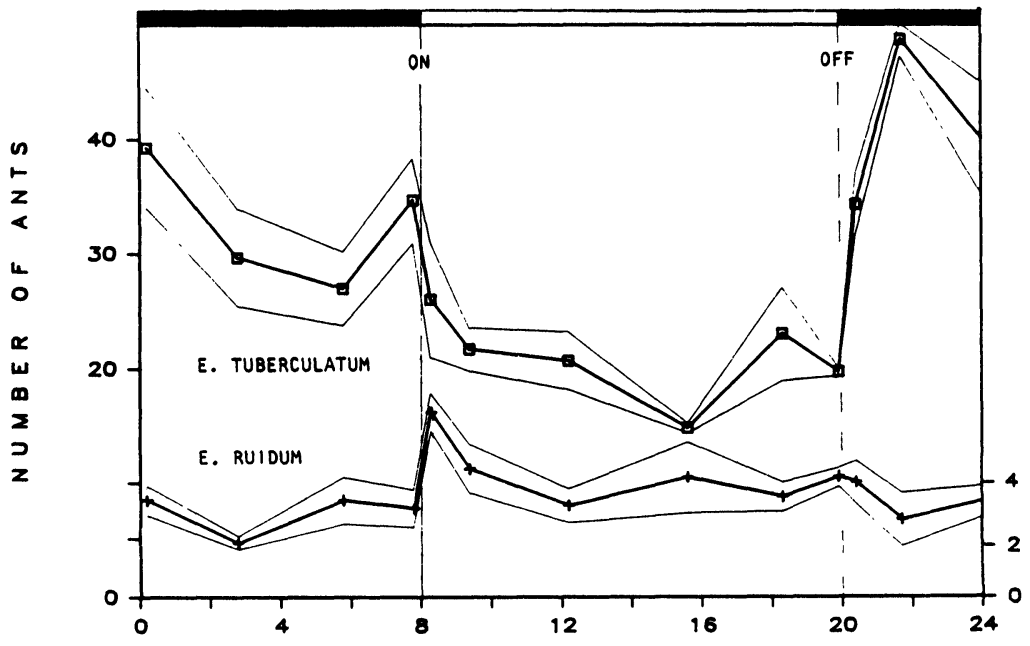

Fig. 2. LD arena rhythm of group of workers from BCI colony. Ants out in arena, mean $\pm \mathrm{SE}$, days as replicates (one-way ANOVA), Mar. 10-14. E. tuberculatum, $P<.001 ; E$. ruidum, $\mathrm{P}=.01$.

again. Counts were started at $0600 \mathrm{Feb} 15$. They rose toward the highest near light-off of what had been the single night light exposure (2000-0800 in Fig. 3). The hourly pattern is consistent from day to day (ANOVA $P<.001$ ). [Still assuming a 24-h free-running period, the peak in Fig. 3 appears somewhat early: the peak hour of a cosine-fitted $(P<.001)$ curve was about 0500 , instead of 0800 (i.e., the new 'dusk' hour) as expected if the rhythm had been completely inverted.]

(In DD Mar. 15-18, the pattern was much less clear, and neither it nor records later in March-April are shown.)

\section{Discussion}

What do these observations say about rhythmic behavior in $E$. tuberculatum? 1) The colony was notably rhythmic in the field, the ants appearing outside the nest primarily at night. 2) A colony fragment in lab constant temperature exhibited a similar rhythm, indicating that it is not simply a reflection of cyclic field temperature. 3) In constant darkness there was evidence for persistence of rhythm, indicating that it is not simply a response to the light-dark cycle of the field, either. 


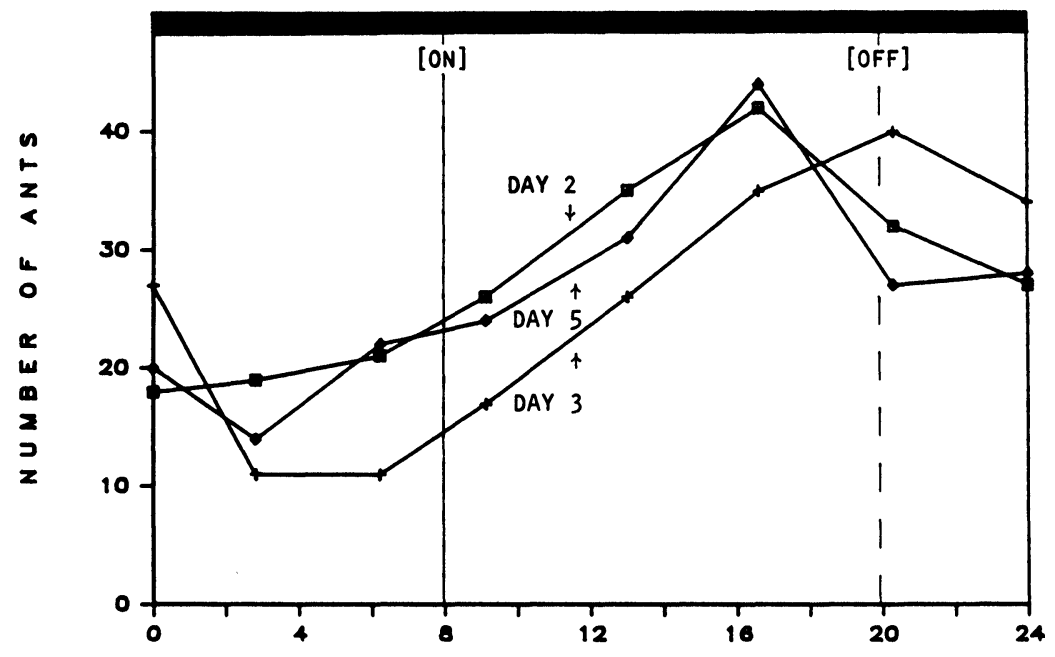

Fig. 3. Same group of E. tuberculatum, in same artificial nest, as in Fig. 2. DD arena rhythm, following single exposure to light for $12 \mathrm{~h}$ starting Feb. 13 at 2000. Day $2=$ Feb. $15-16,3=$ Feb. $16-17,5=$ Feb. $18-19$.

This suggests a rhythm that is circadian in the strictest senseinternally controlled. The evidence stopped short of this for workers of the other two species studied simultaneously, Paraponera (McCluskey \& Brown 1972) and E. ruidum (reported here); there was good rhythm in the lab, but no apparent persistence in constant darkness. However, in those two species, the colony fragment and/or hourly count of ants was much smaller; and this or other limiting conditions may well have obscured display of persistence. On the other hand, it should be noted that the male and female Paraponera studied at the same time did show a persistent rhythm.

There is interesting field evidence for internal control of timing in workers of another BCI species, a leaf-cutting ant (Hodgson 1955). The ants were already in the nest openings an hour before dawn, too early for environmental cues of the approach of dawn; yet even strong light did not reveal them there or bring them forth at earlier hours of the night.

For each species of Ectatomma the LD timing corresponded to that in the field. And in both field and laboratory, the two species were out of the nest at opposite times of day. If these particular nests are indeed characteristic of the species, we would see here an exception to the general trend of similarity in rhythm among the species 
of a genus (McCluskey 1973, 1974). A clear exception is the genus Myrmecocystus, where the members of one subgenus are diurnal, and of another subgenus, nocturnal (Snelling 1976).

The field rhythm for the E. tuberculatum colony was the same as for the one reported by Wheeler (1986), also on BCI, but in July and October, during the rainy season (though the two days were neither rainy nor overcast). My January observations were made during the transition to the dry season. For her colony there was a mass exit at dusk, with continued high foraging during the night, reduced to a very low level through the day. However, in Costa Rica in September she saw much foraging in the morning as well as at night, with no mass exit at dusk. (The habitat was different, e.g., dry forest rather than moist forest as on BCI.)

Long ago as these observations were made, I still remember them vividly - such a clear demonstration of circadian rhythm in the worker caste, not always seen in experience with other species. It made the strenuous around-the-clock observations worthwhile.

\section{SUMMARY}

Workers from one colony each of $E$. tuberculatum and E. ruidum were studied on Barro Colorado Island, then in the laboratory. The peak number out near the field nest was early night for tuberculatum, but during the day for ruidum. In LD the rhythms were likewise opposite. In DD the tuberculatum rhythm persisted. Noteworthy here is the apparent species difference in phase of rhythm, in both field and laboratory; and the persistent rhythm, not always so obvious in the worker caste of ants.

\section{ACKNOWLEDGMENTS}

This research was supported by postdoctoral fellowship NSF 49101 at the Biological Laboratories of Harvard University. I thank W. L. Brown, Jr., for his aid in determining the ant species, as well as in so many other ways while together on the BCI trip, and now for reading the manuscript; and $\mathrm{E}$. $\mathrm{O}$. Wilson for making all this possible, and for such a free use of his laboratory. 


\section{Literature Cited}

Halberg, F., E. A. Johnson, W. Nelson, W. Runge, and R. Sothern. 1972. Autorhythmometry-procedures for physiologic self-measurements and their analysis. Physiology Teacher 1(4): 1-11.

Hodgson, E. S. 1955. An ecological study of the behavior of the leaf-cutter ant Atta cephalotes. Ecology 36: 293-304.

Levings, S. C. 1983. Seasonal, annual, and among-site variation in the ground ant community of a deciduous tropical forest: some causes of patchy species distributions. Ecological Monographs 53: 435-455.

Levings, S. C., and N. Franks. 1982. Patterns of nest dispersion in a tropical ground ant community. Ecology 63: 338-344.

MCCluSKey, E. S. 1973. Generic diversity in phase of rhythm in formicine ants. Psyche 80: 295-304.

MCCluSKey, E. S. 1974. Generic diversity in phase of rhythm in myrmicine ants. J. New York Entomol. Soc. 82: 93-102.

MCCluskey, E. S., AND W. L. Brown. 1972. Rhythms and other biology of the giant tropical ant Paraponera. Psyche 79: 335-347.

SNelling, R. R. 1976. A revision of the honey ants, genus Mrymecocystus (Hymenoptera: Formicidae). Nat. Hist. Mus. Los Angeles County, Science Bull. 24: $1-163$.

WHEELER, D. E. 1986. Ectatomma tuberculatum: foraging biology and association with Crematogaster (Hymenoptera: Formicidae). Ann. Entomol. Soc. Amer. 79: 300-302. 

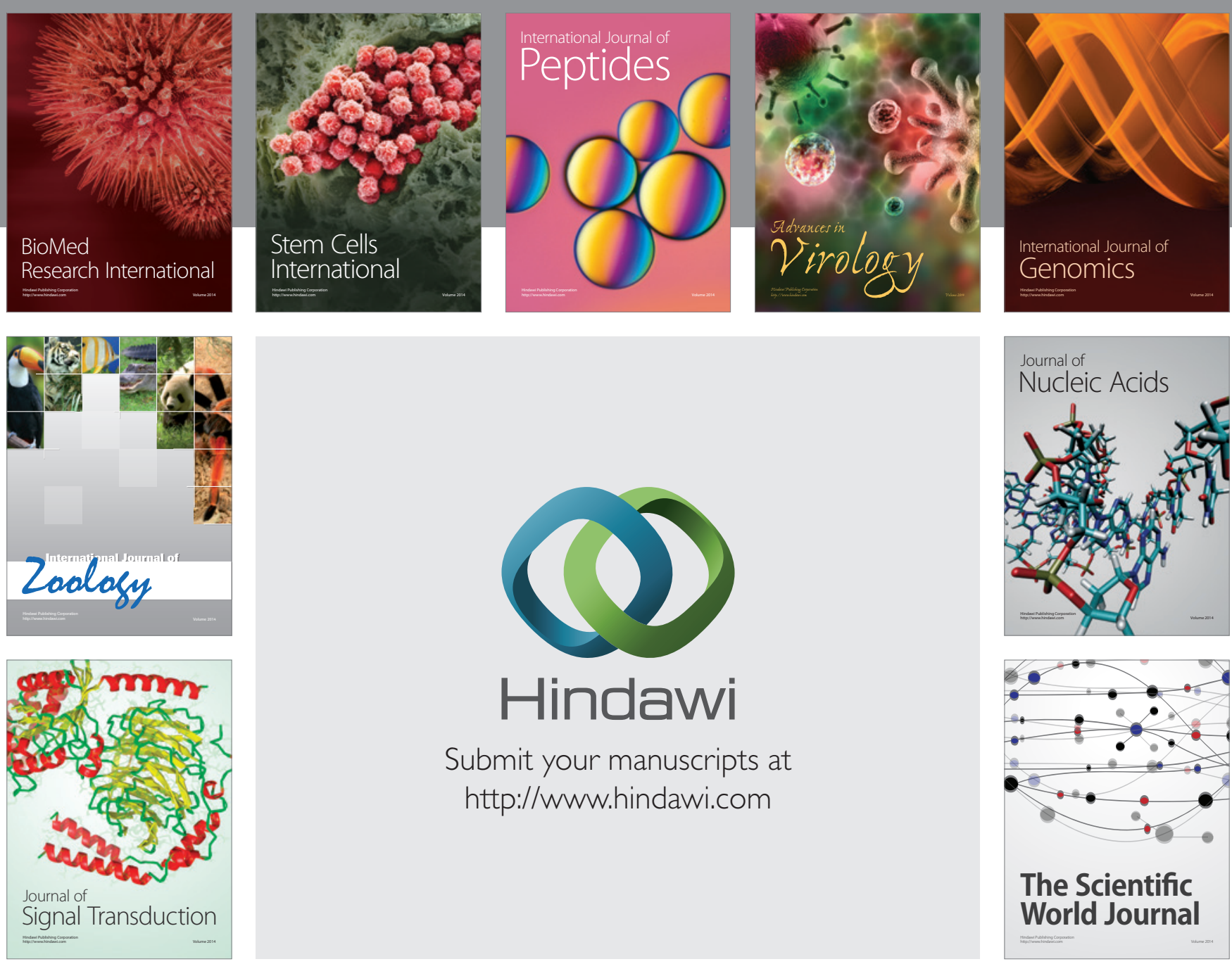

Submit your manuscripts at

http://www.hindawi.com
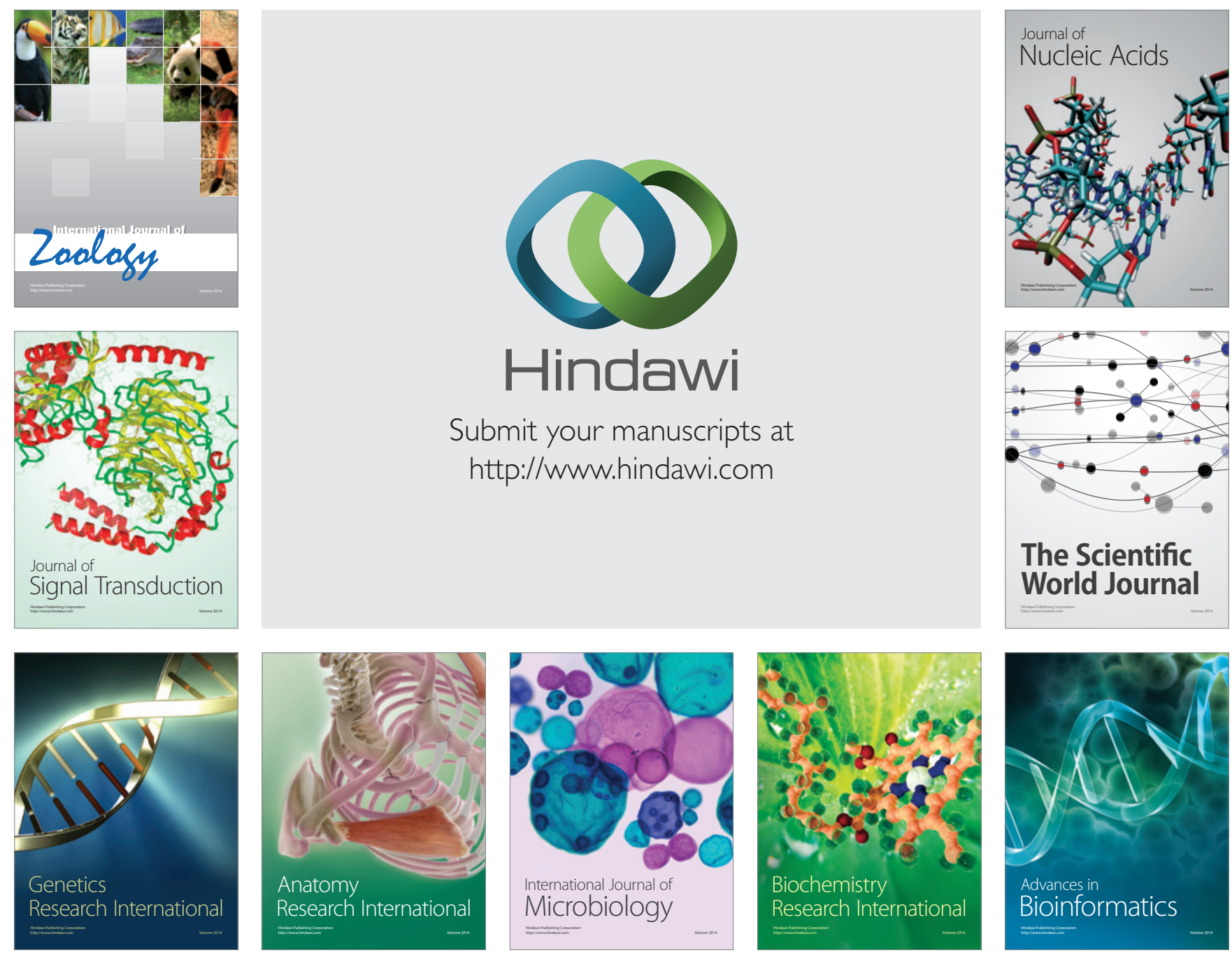

The Scientific World Journal
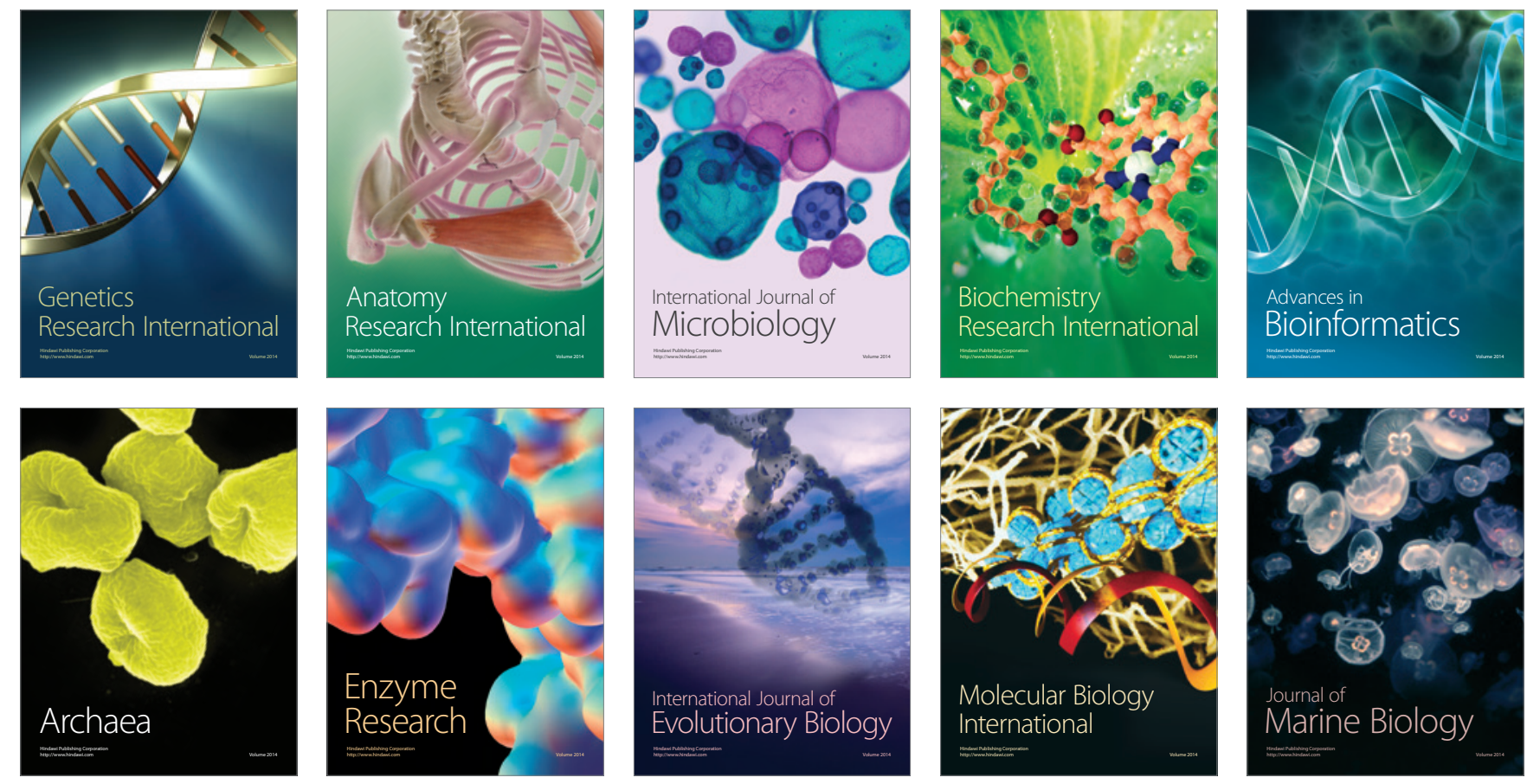